\title{
An Empirical Analysis and Evaluation of the Competitiveness of Chinese Retail Enterprises
}

\section{Tang Zhengwei}

School of Economics, Shanghai University, Shanghai City, China

Email address:

814831615@qq.com

\section{To cite this article:}

Tang Zhengwei. An Empirical Analysis and Evaluation of the Competitiveness of Chinese Retail Enterprises. Science Innovation. Vol. 4, No. 2, 2016, pp. 110-116. doi: 10.11648/j.si.20160402.26

Received: April 10, 2016; Accepted: April 23, 2016; Published: May 5, 2016

\begin{abstract}
As the competition of China's retail industry intensifies, the retail enterprises should do more on self-evaluation objectively and thereby make the right strategic layout in the face of their disadvantages. This paper builds an evaluation system of 15 indicators based on the data of 30 listed retail enterprises of 2014. The principal component analysis is used to process the data, and the evaluation indicators are divided into five dimensions, namely the degree of scale, the speed of development, the capacity of profiting and operating, the solvency and the capacity of utilizing resources of the enterprises. After an objective comparison of the current situation of these enterprises, this paper has comprehensively summarized the empirical results of the sample enterprises, and made an analysis based on the comprehensive ranking, which is helpful for the government to formulate policies supporting the development of the retail industry.
\end{abstract}

Keywords: Retail Company, Evaluation System, Principal Component Analysis

\section{中国零售企业竞争力的实证分析与评价}

\section{唐政伟}

经济学院, 上海大学, 上海市, 中国

\section{邮箱}

814831615@qq.com

\begin{abstract}
摘要：随着中国零售业竞争的加剧, 零售企业在面对自身劣势时更需要客观的审时度势进行自我评价, 以做出合理的 战略布局。本文以 30 家上市零售企业2014年的数据为基础, 通过笁选确定 15 个指标构成评价体系。使用主成分分析法 分析处理数据, 最终将评价指标分为 5 个维度: 企业规模程度、企业发展速度、企业盈利与营运能力、偿债能力、企业 资源利用能力。在客观比较了企业现状后, 综合整理了样本企业的实证结果, 并以综合排名为基础做了分析, 有利于 政府部门制定政策扶持零售业的发展。
\end{abstract}

关键词: 零售企业, 评价体系, 主成分分析

\section{1. 引言}

近些年来，零售行业迅速发展，传统零售业虽然增速 放缓, 但相对其他行业仍较高, 而互联网零售业更呈现井
喷式发展。但是与国际同行对比, 中国的零售业在连锁经 营模式的软硬件方面皆远不如国外, 存在巨大的竞争力差 异。而随着中国改革开放的进一步深入, 国际的大型连锁 零售企业纷纷进入中国市场, 使得零售行业的竞争日趋激 烈。而中国的零售企业面临着管理模式落后、高级人才储 
备不足、资本相对薄弱以及体系架构不合理等竞争劣势 [10], 如何正确评估自身找出短板从而逆境求生成了当务 之急。

而对于竞争力的评估, 中国研究多集中在生产和技 术型的企业, 分析对象如何获得长期发展优势, 但是研 究零售企业竞争力的文章相对较少, 实证的就更少。本 文运用最新的数据, 试图通过数据分析找到中国连锁零 售企业竞争力的薄弱环节，找到零售企业在系统管理、

经营、市场销售等方面存在的缺陷, 以期通过竞争力的 评价, 重新审视企业自身。最后, 通过对连锁零售企业 综合竞争力进行分析和评价, 对竞争力的来源和构成有 更清晰的认识。在实证分析结果的基础上，结合评价指 标的特点与内涵, 指出了中国连锁零售企业的发展现状 及存在的问题。

\section{2. 文献综述}

评价连锁零售企业的竞争力, 必须分清其内在竞争 力的组成要素 [12], 如此, 零售企业才能对症下药, 正 确的评估自身优势与劣势, 调整发展战略并优化管理。 政府部门知道企业需要什么, 才能制定合适的扶持政策 鼓励其发展。

国际对于零售业的相关研究主要有以下几种:

赫兰德提出的手风琴理论 [1] 认为: 零售业态就像手 风琴一样, 会由宽变窄, 再由窄变宽, 即零售组织的经营 范围从综合到专业, 再从专业到综合, 如此循环持续下去。

迈克尔 - 利维 (Michael Levy) 和巴顿 - A - 韦茨 (Barton A Weitz) [2]指出: 店址选择、顾客忠诚度、成 本控制、与供应商的关系、分销系统和信息管理能力构成 了零售企业的核心竞争力。

哈佛教授迈克尔・波特 [3]指出：企业凭借自己所特 有的资源所产生的不同于其他企业的关键竞争力和竞争 优势就是自身的核心竞争力。它是独一无二的, 是企业追 求持续竞争优势的核心所在, 也是企业能否持续稳定发展 的关键。

哈佛大学的麦克奈尔教授 [4]提出: 零售组织变革有 着周期性的发展趋势, 都遵循着从低成本、低价格、低毛 利到高费用、高毛利、高价格的不断轮回的过程。

而中国的研究主要有以下观点:

张秋白在《如何提升零售企业核心经营能力》中 [9] 指出: 企业的核心竞争力主要在主要技术力、流程控制力、 经营管理力、营销服务力、企业文化力五个方面。

宋思根 [6]以上海市民为研究对象, 通过对消费者决 策形态的实证及其与零售业态惠顾意向、零售商店形象 之间的关系分析指出：专卖店、大型超市与折扣店的市 场定位相对准确, 而互联网商店和便利店的定位则需进 一步明确。

刘星原 [7]认为连锁零售企业竞争力包括六个方面的 要素: 企业员工学习培训系统和优秀的经营管理人才、市 场信誉和知名度及对顾客需求满足程度、充裕的资金、技 术创新、经营场所的选址、高水平管理和低成本运。

杨娇娇 [8] 从2006-2008年的上市零售企业年报中提 取 24 个财务和非财务指标来评价零售企业竞争力。指出企
业竞争力表现为企业的资产管理能力、人力资源能力、规 模和成长能力。

付晓 [16]以重庆百货为例, 在实证分析后指出: 企业 竞争力的 4 个能力因子方面, 偿债能力和成长能力起到了 很重要的作用。同时, 偿债能力、成长能力、盈利能力和 营运能力是相互作用和促进的, 只有企业的四个因子都处 于一个良性循环的发展过程, 企业才能提高自身竞争力, 持续、健康发展。

李伅辉 [17]在研究中认为: 基于客户价值视角研究零 售业的竞争力才是最佳的选择, 并且进一步认为客户价值 取决于竞争能力（核心竞争力）, 竞争能力又取决于核心 资源, 客户价值、竞争能力和核心资源构成了零售企业竞 争力体系。

从以上研究文献中可知, 零售企业的综合竞争力是多 维度的, 本文假设中国零售企业的外部条件基本相同, 企 业文化等隐性因素影响不大, 采用内部可以量化的财务指 标等数据进行评价模型构建。

\section{3. 模型构建与实证处理}

\section{1. 评价指标选取}

本文借鉴了中国以及国际上对于零售企业的研究成 果并结合中国零售企业的自身特征, 根据指标的重要性、 可获得性以及模型评价的全面性, 最终选取了如下 20 个 指标 [11]（涉及资产负债表中的数据均采用年初年末平 均值）:

(1)销售毛利率; (2)销售净利率; (3)净资产收益率; (4)总 资产净利润率

(5)流动比率; (6)速动比率; (7)资产负债率; (8)存货周转 率

(9)应收账款周转率; (10流动资产周转率; (11)总营业收 入; 12营业利润

(13)总资产; (14)固定资产总额; (15)无形资产总额; (16)净利 润; (17)营业收入增长率

(18)营业利润增长率; (19)总资产增长率; (20)总资产周转 率

本文从中国 30 家大型上市零售企业中提取这 20 个指 标的原始数据, 作为研究的输入数据, 并运用主成分分析 法进行分析和处理。

\section{2. 样本选择与数据选取}

考虑到模型分析数据的代表性、重要性和可获得性, 本文使用上市公司数据进行实证分析。上市公司的数据需 要经过相关审计, 相对来说具有更加可信, 上市公司的年 报中相关数据比较详细, 数据的获取也比较容易。

通过Wind咨询查询了解到已有超过 80 家零售企业在 国内上市, 考虑到实证研究的全面性、可操作性, 在实际 的数据提取中结合既定的评价指标, 无法得到相关数据的 企业予以剔除 [16]。最后选取 30 家企业数据作为样本企业, 样本企业的具体情况如下表1所示。 
表1 实证数据来源企业。

\begin{tabular}{|c|c|c|c|c|c|}
\hline 证券代码 & 企业名称 & 证券代码 & 企业名称 & 证券代码 & 企业名称 \\
\hline 600859 & 王府井 & 600774 & 汉商集团 & 000564 & 西安民生 \\
\hline 002024 & 苏宁云商 & 600824 & 益民集团 & 000715 & 中兴商业 \\
\hline 600814 & 杭州解百 & 600628 & 新世界 & 600712 & 南宁百货 \\
\hline 000759 & 中百集团 & 600778 & 友好集团 & 600693 & 东百集团 \\
\hline 600827 & 百联股份 & 000560 & 昆百大A & 600729 & 重庆百货 \\
\hline 600694 & 大商股份 & 000417 & 合肥百货 & 000785 & 武汉中商 \\
\hline 000501 & 鄂武商A & 000987 & 广州友谊 & 600738 & 兰州民百 \\
\hline 000679 & 大连友谊 & 600682 & 南京新百 & 002251 & 步步高 \\
\hline 600361 & 华联综超 & 600785 & 新华百货 & 600280 & 中央商场 \\
\hline 601933 & 永辉超市 & 600327 & 大东方 & 600723 & 首商股份 \\
\hline
\end{tabular}

由于各平台统计数据有所偏差, 故以目前中国最权威 的Wind咨询作为数据来源, 从中搜集 30 家样本企业的 2014 年年报（许多企业2015年年报尚未公布），提取具体的指 标数据, 并以中国连锁经营协会的数据进行检验 [10]。将 30 家上市连锁零售企业的指标数据输入SPSS软件并采用 因子分析法进行分析。

\section{3. 指标评价}

指标评价可以比较各个指标的鉴别度, 将鉴别度高的 指标予以保留, 提高评价体系的科学性与有效性。主要步 骤如下：求出样本在各指标上的总分一一将各指标总分 按照升序进行排列——>找出高低分组 $27 \%$ 处的分数 $-\longrightarrow$ 根据临界分数将样本分成高低两组, 命名为 $a$ 组、 $b$ 组 $-\longrightarrow$ 采用独立样本 $\mathrm{T}$ 检验的方法分析 $\mathrm{a}$ 组与 $\mathrm{b}$ 组在各个指标平均 数上的差异显著性一一删除 $\mathrm{T}$ 检验结果未达到显著差异 的指标。

数据结果显示销售毛利率、应收账款周转率、资产负 债比率、固定资产总额、无形资产总额这 5 个指标的 $\mathrm{T}$ 值大 于 0.05 , 未达到显著水平, 鉴别度较低, 故予以剔除。对 余下的 15 个指标分别排序并编号。

\section{4. 实证研究的因子分析过程}

在分析之前需要使用KMO 检验与Bartlett' $\mathrm{s}$ 球形检 验来检验指标之间的相关性。分析结果如下表, KMO检验 值是 0.628 , 大于做因子分析要求的值 0.5 , 表示适合做 因子分析。Bartlett球度检验结果中的相伴概率是 0.000 , 小于 0.05 , 也表明选取的指标适合做因子分析。数据检验 结果见表 2 :

表2 KOM and Bartlett's检验。

\begin{tabular}{lll}
\hline \multicolumn{2}{l}{ 取样足够度的 Kaiser-Meyer-01kin度量 } & .628 \\
\hline \multirow{3}{*}{ Bartlett的球形度检验 } & 近似卡方 & 647.896 \\
& df & 105 \\
& Sig. & .000 \\
\hline
\end{tabular}

数据来源: 各上市连锁零售企业2014年年鉴及SPSS分析结果
变量共同度表示提取的全部公共因子对于原始变量 的总方差的解释程度。具体如下表 3 , 提取一栏为各原始变 量的共同度, 说明提取的公共因子分别解释了营业收入、 总资产、净利润这三个指标所包含信息的的 $98.7 \%$ 、96. 9\%、 95. $7 \%$ 。

由SPSS得出的下表可知, 利用因子分析法提取的公共 因子可以很好地解释原有原始变量的信息, 可以较好的评 价国内零售企业竞争力。

表3 公因子方差。

\begin{tabular}{lcc}
\hline & 初始 & 提取 \\
\hline 销售净利率 & 1.000 & .772 \\
资产净利率 & 1.000 & .912 \\
净资产受益 & 1.000 & .783 \\
存货周转率 & 1.000 & .780 \\
流动资产周转率 & 1.000 & .909 \\
总资产周转率 & 1.000 & .761 \\
总资产增长率 & 1.000 & .949 \\
营业利润增长率 & 1.000 & .906 \\
营业收入增长率 & 1.000 & .881 \\
流动比率 & 1.000 & .820 \\
速动比率 & 1.000 & .745 \\
总资产 & 1.000 & .969 \\
营业收入 & 1.000 & .987 \\
营业利润 & 1.000 & .937 \\
浄利润 & 1.000 & .957 \\
\hline
\end{tabular}

提取方法: 主成份分析

数据来源: 各上市连锁零售企业2014年年鉴及SPSS分析结果

接下来分析因子的方差贡献率: 


\begin{tabular}{|c|c|c|c|c|c|c|c|c|c|}
\hline \multirow[b]{2}{*}{ 成份 } & \multicolumn{3}{|c|}{ 初始特征值 } & \multicolumn{3}{|c|}{ 捉取平方和载入 } & \multicolumn{3}{|c|}{ 旋转平方和载入 } \\
\hline & 合计 & 方差的 $\%$ & 䍗积 \% & 合计 & 方差的 $\%$ & 䍗积 \% & 合计 & 方差的 \% & 赫积 \% \\
\hline 1 & 3.692 & 24.615 & 24.615 & 3.692 & 24.615 & 24.615 & 3.289 & 21.924 & 21.924 \\
\hline 2 & 3.282 & 21.879 & 46.494 & 3.282 & 21.879 & 46.494 & 2.682 & 17.881 & 39.806 \\
\hline 3 & 2.690 & 17.936 & 64.431 & 2.690 & 17.936 & 64.431 & 2.466 & 16.442 & 56.248 \\
\hline 4 & 2.311 & 15.405 & 79.836 & 2.311 & 15.405 & 79.836 & 2.329 & 15.527 & 71.775 \\
\hline 5 & 1.091 & 7.271 & 87.107 & 1.091 & 7.271 & 87.107 & 2.300 & 15.332 & 87.107 \\
\hline 6 & .807 & 5.383 & 92.490 & & & & & & \\
\hline 7 & .512 & 3.414 & 95.904 & & & & & & \\
\hline 8 & .252 & 1.677 & 97.581 & & & & & & \\
\hline 9 & .148 & .990 & 98.571 & & & & & & \\
\hline 10 & .102 & .682 & 99.253 & & & & & & \\
\hline 11 & .061 & .406 & 99.659 & & & & & & \\
\hline 12 & .024 & .162 & 99.821 & & & & & & \\
\hline 13 & .016 & .105 & 99.925 & & & & & & \\
\hline 14 & .009 & .062 & 99.987 & & & & & & \\
\hline 15 & .002 & .013 & 100.000 & & & & & & \\
\hline
\end{tabular}

数据来源: 各上市连锁零售企业2014年年鉴及SPSS分析结果

图1 解释的总方差。

由上图可知特征值大于 1 的主成分因子有五个, 累计贡献率为 $87.106 \%$ 。表明解释程度较高, 所以用这五个因子来分 析大型零售企业竞争力是合理的。

接下来还需要对成份矩阵进行正交转轴, 使得具有综合性的初始公共因子可以区分开来。令各原始指标的载荷尽 量靠近1或者 0, 成份矩阵见图2。

\begin{tabular}{|c|c|c|c|c|c|}
\hline & \multicolumn{5}{|c|}{ 成份 } \\
\hline & 1 & 2 & 3 & 4 & 5 \\
\hline 营业利润增长率 & .770 & -.346 & .220 & -.267 & -.272 \\
\hline 总资产净利润率 & .739 & .536 & -.182 & .023 & .211 \\
\hline 销售净利率 & .689 & -.145 & -.178 & .489 & .071 \\
\hline 总资产亿元 & -.657 & .549 & .122 & .470 & .000 \\
\hline 净资产收益率 & .649 & .324 & .421 & .282 & .004 \\
\hline 营业利润亿元 & .614 & .391 & .239 & -.216 & -.551 \\
\hline 净利润亿元 & .002 & .857 & .232 & .205 & -.355 \\
\hline 总资产周转率 & .059 & .723 & .051 & -.481 & .007 \\
\hline 营业收入亿元 & -.637 & .691 & .082 & .311 & -.035 \\
\hline 营业收入增长率 & .137 & .005 & .832 & .265 & .316 \\
\hline 总资产增长率 & .283 & -.083 & .786 & .403 & .287 \\
\hline 流动比率 & .348 & .148 & -.634 & .522 & -.043 \\
\hline 速动比率 & .321 & .439 & -.629 & .182 & .142 \\
\hline 流动资产周转率 & -.077 & .406 & .272 & -.789 & .202 \\
\hline 存货周转塐 & .332 & .417 & -.288 & -.349 & .540 \\
\hline
\end{tabular}

数据来源: 各上市连锁零售企业2014年年鉴及SPSS分析结果

图2 成份矩阵。 
本文使用最大变异法进行正交转轴, 实现了原始指标载荷的两极分化。使得公共因子易于鉴别和定义。具体如下 图3（来源于SPSS分析结果）。

\begin{tabular}{|c|c|c|c|c|c|}
\hline & \multicolumn{5}{|c|}{ 成份 } \\
\hline & 1 & 2 & 3 & 4 & 5 \\
\hline 营业收入亿元 & .983 & -.095 & -.018 & .013 & .102 \\
\hline 总谯产亿元 & .973 & -.009 & .083 & -.120 & -.013 \\
\hline 营业利润增长赍 & -.834 & .036 & .185 & -.056 & .415 \\
\hline 流动比率 & .065 & .864 & -.216 & .140 & .049 \\
\hline 流动资产周转率 & .000 & -.756 & -.036 & .546 & .193 \\
\hline 销售净利率 & -.342 & .755 & .274 & .062 & .078 \\
\hline 速动比率 & .136 & .597 & -.281 & .530 & .102 \\
\hline 总资产增长率 & -.042 & .014 & .966 & -.115 & .033 \\
\hline 营业收入增长率 & .055 & -.176 & .918 & -.059 & .021 \\
\hline 净资产收益赍 & -.087 & .279 & .622 & .195 & .522 \\
\hline 存货周转率 & -.081 & .031 & -.057 & .876 & -.036 \\
\hline 总资产净利润率 & -.124 & .436 & .155 & .716 & .414 \\
\hline 总资礼周转率 & .229 & -.353 & -.132 & .590 & .467 \\
\hline 营业利洞亿元 & -.248 & -.001 & .058 & .106 & .928 \\
\hline 净利润亿元 & .626 & .038 & .113 & .126 & .732 \\
\hline
\end{tabular}

图3 转轴后的成份矩阵。

从转轴后的因子载荷来看, 各指标均有更高的载荷量, 解释程度更高, 按照每个子指标的最大解释量来分类, 15 个子指标可归入到五个大的维度中, 本文将五大维度分别 命名为: 企业的规模程度、企业盈利与营运能力、企业偿 债能力、企业发展速度、企业资源利用能力 [14]。其具体 分类见表4:

表4 竞争力评价体系。

\begin{tabular}{|c|c|c|c|}
\hline 维度 & 测量指标 & 指标代码 & 因子负荷 \\
\hline \multirow{4}{*}{ 规模程度（X1） } & 总资产 & (12) & 0.973 \\
\hline & 营业收入 & (13) & 0.983 \\
\hline & 营业利润 & (14) & 0.928 \\
\hline & 净利润 & (15) & 0.732 \\
\hline \multirow{3}{*}{$\begin{array}{l}\text { 盈利与营运能力 } \\
\text { (X2) }\end{array}$} & 销售净利率 & (1) & 0.755 \\
\hline & 总资产净利润率 & (2) & 0.716 \\
\hline & 净资产收益率 & (3) & 0.622 \\
\hline \multirow{2}{*}{ 偿债能力（X3） } & 流动比率 & (4) & 0.864 \\
\hline & 速动比率 & (11) & 0.597 \\
\hline \multirow{3}{*}{ 发展速度（X4） } & 总资产增长率 & (7) & 0.966 \\
\hline & 营业利润增长率 & (8) & 0.415 \\
\hline & 营业收入增长率 & (9) & 0.918 \\
\hline \multirow{3}{*}{$\begin{array}{l}\text { 资源利用能力 } \\
\text { (X5) }\end{array}$} & 存货周转率 & (4) & 0.876 \\
\hline & 流动资产周转率 & (5) & 0.546 \\
\hline & 总资产周转率 & (6) & 0.590 \\
\hline
\end{tabular}

根据正交转轴后的因子载荷矩阵上各原始指标载荷 数值可得到企业竞争力在各单项因子的得分函数, 由各单 项因子的得分函数推导出企业竞争力综合评价函数如下:

$$
\mathrm{F}=28.26 \% * \mathrm{X} 1+25.12 \% * \mathrm{X} 2+20.59 \% * \mathrm{X} 3+17.69 \% * \mathrm{X} 4+8.35 \% * \mathrm{X} 5
$$

根据SPSS分析结果得到下表5（按照综合得分从高到 低排名）。
表5 样本企业各单项因子及综合排名情况。

\begin{tabular}{lllllll}
\hline 企业名称 & X1排名 & X2排名 & X3排名 & X4排名 & X5排名 & F排名 \\
\hline 苏宁云商 & 1 & 12 & 8 & 13 & 30 & 1 \\
大商股份 & 3 & 13 & 15 & 5 & 1 & 2 \\
南京新百 & 15 & 17 & 1 & 18 & 18 & 3 \\
杭州解百 & 20 & 6 & 4 & 1 & 21 & 4 \\
广州友谊 & 16 & 1 & 28 & 6 & 17 & 5 \\
百联股份 & 2 & 20 & 21 & 26 & 2 & 6 \\
首商股份 & 7 & 5 & 20 & 2 & 8 & 7 \\
永辉超市 & 4 & 25 & 5 & 9 & 3 & 8 \\
王府井 & 6 & 7 & 29 & 7 & 6 & 9 \\
中央商场 & 11 & 4 & 2 & 28 & 7 & 10 \\
合肥百货 & 10 & 9 & 13 & 15 & 9 & 11 \\
重庆百货 & 5 & 22 & 26 & 8 & 5 & 12 \\
鄂武商A & 8 & 23 & 3 & 19 & 4 & 13 \\
益民集团 & 25 & 11 & 6 & 11 & 15 & 14 \\
东百集团 & 30 & 2 & 10 & 27 & 16 & 15 \\
兰州民百 & 29 & 3 & 12 & 22 & 20 & 16 \\
步步高 & 14 & 24 & 9 & 17 & 10 & 17 \\
新华百货 & 21 & 21 & 14 & 10 & 12 & 18 \\
新世界 & 28 & 15 & 7 & 21 & 19 & 19 \\
中兴商业 & 23 & 19 & 23 & 4 & 26 & 20 \\
友好集团 & 12 & 14 & 27 & 23 & 14 & 21 \\
大东方 & 18 & 26 & 17 & 12 & 13 & 22 \\
华联综超 & 9 & 18 & 24 & 24 & 23 & 23 \\
大连友谊 & 17 & 10 & 25 & 30 & 22 & 24 \\
中百集团 & 13 & 29 & 18 & 16 & 11 & 25 \\
昆百大A & 24 & 8 & 19 & 29 & 24 & 26 \\
西安民生 & 19 & 16 & 16 & 25 & 28 & 27 \\
武汉中商 & 22 & 27 & 22 & 14 & 25 & 28 \\
汉商集团 & 27 & 30 & 11 & 3 & 29 & 29 \\
南宁百货 & 26 & 28 & 30 & 20 & 27 & 30 \\
\hline
\end{tabular}

数据来源：各上市连锁零售企业2014年年鉴及SPSS分析结果 


\section{4. 实证结果分析} 结论:

根据以上实证分析结果以及初步比较本文得出以下

\section{1. 企业规模对竞争力影响巨大, 但并不唯一}

从表 3.8 可知, 苏宁在规模一项得分最高, 同时在其 他几项也有较好表现, 故能排名第一。另外由表 3.8 可知 在规模一项得分较高的企业一般在其他方面表现都会比 较好, 例如规模排名分别处于第二、三、四、五的百联股 份、大商股份、永辉超市、重庆百货, 它们在其他几个方 面一般表现不错。当然, 也并不一定会在所有维度都表现 优异。而在规模排名里靠后的企业, 综合竞争力一般较弱, 一方面由于规模因子所占权重较大, 另一方面规模排名靠 后的企业在其他方面也表现较弱。

以上现象的主要原因是: 企业营运系统的各个环节都 会受到企业规模的影响, 营运规模决定了企业的采购规模, 采购规模决定了企业采购商品时与供应商的议价能力。规 模经济的优势可以以较低价格获得商品, 从而形成成本上 的优势。营运规模影响企业的市场占有率, 较大的运营规 模反映了企业门店扩张的能力, 企业可以在更广阔的市场 参与竞争, 获得更多的市场份额, 扩大品牌影响力。所以 运营规模的扩大对提升连锁零售企业竞争力有重要影响。

但是企业运营规模与竞争力之间的关系并不是完全 成正比的, 例如重庆百货与鄂武商 $\mathrm{A}$, 规模排名分别为第 5 名与第 8 名, 而广州友谊、杭州解百的规模排名分别为第 16名、20名, 但是广州友谊、杭州解百的综合排名却远超 重庆百货、鄂武商 $A$, 这主要得益于两家公司在盈利与营 运能力、成长能力等方面的优异表现。

\section{2. 先进技术提高综合竞争力}

先进的信息技术与系统有利于提高综合竞争力, 大型 零售企业不仅有自己的网上平台, 更有众多的实体店作为 支撑, 同时还有庞大的供应链和销售网络以及客户群需要 维护。而信息技术与系统是将这一切进行整合的核心所在。 例如综合排名前三的苏宁云商、大商股份、南京新百, 都 在近几年提出多个信息化发展战略, 大力引进信息化系统 与管理工具, 不断扩大完善自己的数据库网络。其中尤以 苏宁云商为代表, 今年来先后引入了商业ERP、供应链管 理SCM、商业智能BI与客户关系管理CRM等系统网络。用以 提高运营效率、降低成本、建设售后服务的组织和服务流 程体系。

\section{3. 上市连锁零售企业良莠不齐, 竞争力差异巨大}

常理来说, 只有盈利能力强、管理模式先进、财务状 况良好的企业才会上市。但是许多上市企业在经过多年的 发展后可能会出现管理运营体制僵化、不思变革, 同时面 对新兴对手的竞争与市场需求的不断变革, 容易逐渐衰退。 例如武汉中商与南宁百货, 它们的综合排名靠后。一方面 规模较小, 另一方面财务指标与财务结构上也不尽合理。 如存货周转率、销售净利率、流动比率等指标都较低。表 明这些企业存在存货变现、资金周转问题, 极有可能因为
资金断裂而发生问题。而查询这两家企业在2010至2013 年的财务指标取平均数, 均高于当前的数据, 一定程度上 印证了上述推论。因此, 需要企业统筹供应链, 降低成本, 整合销售渠道, 提高商品变现能力, 降低运营风险。另一 方面需要调整财务结构, 从而降低财务风险。

\section{5. 结论与展望}

\section{1. 结论}

本文通过因子分析法最终选定 15 个指标构建连锁零 售企业竞争力评价体系，体系从企业规模能力、盈利与营 运能力、偿债能力、发展速度、资源利用能力五个维度综 合评价零售企业的竞争力。本文数据来源于 30 家中国上市 的大型零售企业2014年年报数据, 运用SPSS进行处理, 得 出的得分与排名结果也符合样本企业的实际发展情况, 表 明评价体系是合理的。

在实证分析的结果中, 本文经过初步比较与总结, 得 出了连锁零售企业的三个推论: 企业规模对竞争力影响巨 大, 但并不唯一; 先进技术可以提高企业综合竞争力; 上 市连锁零售企业经营管理水平不一定高, 竞争力差异巨大。

\section{2. 展望}

（1）本文选取的是2014年的面板数据，并没有考虑 时间序列的变化与影响, 即只对行业进行了平行比较, 对 企业自身各种指标的动态变化所带来的影响并未纳入模 型的考虑范围。故后期研究可以考虑将企业自身的动态变 化及影响纳入模型之中。

（2）本文选取的多为可以量化的财务指标，对一些 数据难以获得或是难以量化的软性指标都予以了回避。一 定程度上削弱了模型的解释能力。后续研究可以通过调查 问卷、专家打分等方式将定性指标加入到评价体系中, 增 加其说服力与科学性。

（3）本文的样本企业都是上市企业，而实际上许多 并未上市的零售企业在各方面都有优异的表现, 将它们纳 入研究范围一方面可以增加结论的有效性, 另一方面也许 可以发现许多仅以上市企业作样本所发现不了的现象与 问题。

\section{参考文献}

[1] S. C. Hollander. Retailing: Cause or Effect [A]. In W. S. Eecker (Ed), Emerging Concepts in Marketing [C]. Chicago: American Marketing Association. 1962: 220-230.

[2] 迈克尔 - 利维, 巴顿 - 韦茨. 零售学精要 [M]. 机械工业出版 社, 2000。

[3] 迈克尔・波特. 竞争伦 [M]. 中心出版社, 2003。

[4] M. P. M cNair. Trends in Large Scale Retailing [J]. Harvard Business Review, Vol, 10, 1931: 30-39. 
[5] 托马斯 - B - 达文波特等. 信息技术的商业价值 [M], 北京, 中国人民大学出版社, 2000。

［6］宋思根. 零售形象、业态惠顾意向与消费者决策形态关系的 实证研究 [J]. 经济科学, 2006. 4。

[7] 刘星原. 零售企业核心竞争力研究 $[J]$. 当代经济科学, 2006。

[8］杨娇娇. 中国零售业上市公司竞争力评价体系的研究 [D]. 吉林大学, 2010。

[9] 张秋白. 如何提升零售企业核心经营能力 [D]. 北京市财贸 管理干部学院学报, 2006, 1:004。

[10］2013-2014中国连锁零售企业经营状况分析报告. 中国连锁 经营协会。

[11] 杨宏林. 基于主成分分析的企业竞争力模糊评价模型研究 [J]. 当代财经, 2004 (4).126-128。
[12］朗・西韦尔. 核心竞争力 $[M]$, 华夏出版社, 2003。

[13] 傅贤治. 企业竞争力结构与核心竞争力的形成 [N], 经济管 理, 2001(12)。

[14] 朱欣民. 打造零售企业核心竞争力 $[\mathrm{N}]$, 商业时代理 论, 2005 (8)。

[15］wind咨询. 各上市企业2014年年报 [Z].wind咨询官网, 2015。

[16] 付晓. 大型连锁零售企业竞争力实证研究一一以重庆百货 公司为例 [D].2015。

[17] 李伅辉, 康海燕. 基于客户价值的零售企业竞争力体系探讨 [J]. 华东经济管理, 2014, 28(01):143-146。 